\title{
TYPES AND FUNCTIONS OF CITATIONS IN MASTER'S THESES ACROSS DISCIPLINES AND LANGUAGES
}

\author{
Raheleh Bahadorfar and Javad Gholami
}

\begin{abstract}
Citation is an essential and common feature of academic writing and is used by academic writers to achieve different purposes. This study investigated disciplinary variations in terms of citation practices in the genre of Master's theses with a specific focus on discussions. To this end, sixty discussions produced by MA/MS students of two key universities in Iran from both hard and soft disciplines were analyzed in terms of citation types and functions. The medium of writing whether English or Persian was also taken into account for its probable influence on the employed citation practices. The results revealed that integral citations were used more frequently by writers in soft knowledge fields, allowing them to make evaluations, whereas non-integral citations were mostly used by hard discipline writers. As for rhetorical functions, Support and Comparison were the dominant functions in these text types. However, there existed subtle differences both in the degree and the way these writers draw intertextual links to their disciplines. The findings can be of considerable help to EAP instructors and thesis supervisors to raise their students' awareness and refine their understanding of citation strategies in thesis writing.
\end{abstract}

\section{Keywords}

citation strategies, disciplinary variation, discourse community, discussion, Master's thesis

\section{Introduction}

Citation is defined as a rhetorical feature which involves a reference "to something external to the citing text" (Pecorari 2006: 6). Besides, its increasing significance as well as its vital role in different ways of construction of facts by writers via their communication practices is further evidence for the importance of citations (Hyland 1999). Academic writers can use citations for different purposes among which are evaluating relevant sources, supporting an author's claim, and providing those who are on the threshold of joining their research community with a longer list of readings (Smith 1981).

Citation has been of much interest to English for Academic Purposes (EAP) researchers (e.g. Harwood 2009, Hyland 2000, Swales 1986, 1990), information scientists (White 2004), and sociologists of knowledge (Petrić 2007), who have conducted many studies on its role in scientific discourse using various methods and instruments. Some of these scholars have investigated cultural differences in 
citation use (Pennycook 1996, Mur Dueñas 2009, Hu \& Wang 2014), diachronic development of citation (Bazerman 1988), patterns of the use of linguistic elements accompanying citation (e.g. Charles 2006a, 2006b, Hawes \& Thomas 1997, Hyland 2002), and different types of citation, in particular (e.g. Hyland 1999, 2002, Swales 1990). Swales (1990) has classified citations into integral and non-integral citations according to their linguistic environment. Further subtypes have been introduced by other scholars considering both linguistic and rhetorical analysis of citations (Thompson \& Tribble 2001, Thompson, P. 2005).

In recent years, the patterns of citation use have been explored in written academic discourse, specifically in the genre of Research Articles (RAs) (e.g. Hyland 1999, 2000, Harwood 2009, Hewings et al. 2010, Shooshtari \& Jalilifar 2010). Hyland (1999) carried out a study on RAs; the corpus consisted of one article from each of ten leading journals across eight disciplines. The analysis revealed that softer disciplines used more citations in the construction of their texts and the use of integral citations was more dominant in these text types. However, writers in hard disciplines used more non-integral citations. Harwood (2009) explored citation functions employed by sociologists and computer scientists in an interview-based study and identified eleven functions based on the informants' words. While the sociologists used citations more for engaging the reader, the computer scientists employed them more for signposting. In a more recent study, Mansourizadeh and Ahmad (2011) conducted a case study on citation practices in research articles produced by non-native experts and papers written by novice writers from the same discipline (chemical engineering) and with the same language background. They found that the writers mostly used non-integral citations in their text and that novice writers used citations to a lesser degree compared to the expert ones. Besides, novices mainly used citations with the function of Attribution which is used to indicate the knowledge of the literature, while experts used more complex citation functions such as Support and Establishing links between sources in the construction of their texts.

Citation strategies have also been examined in texts produced by students across disciplines (e.g. Dong 1996, Thompson, C. 2005). Dong (1996) reported on the use of citations by three non-native $\mathrm{PhD}$ students in producing drafts of thesis introduction sections with the help from English speaking advisors. The study revealed what difficulties students run into in the production of these text types while highlighting the prominent role played by the advisors in construction of new knowledge claims. In another study, Petrić (2007) identified rhetorical citation functions in high- and low-graded Master's theses in gender studies. The findings showed that both sets of theses used citations mainly for attribution or "knowledge display" - one of the functions of citations in students' writing and 
the percentage of this citation function was higher in low-rated theses, whereas the percentages of other more complex citation functions, such as showing a good knowledge of the literature and demonstrating analytic ability, were higher in the high-rated theses.

Most of these studies have focused on doctoral dissertations. Few have investigated the nature of theses in MA/MS programs. For instance, Samraj (2008) examined the use of citations and first person pronoun in introduction sections of Master's theses from three disciplines. Her study revealed varying degrees of relation to previous research with philosophy theses being the strongest in foregrounding the student's voice. On the other hand, biology students formed a stronger connection to previous work and linguistics had a central position in this regard.

We decided to explore citation strategies in discussion sections (DSs) of theses since they appear to be one of the most significant parts of the RAs in which the authors bring out the plus points of the result in a more convincing way. Despite their significant role in shaping a good research, the use of citation strategies in DSs of theses has received scant attention in the literature. If Results, according to Swales and Feak (1994: 195), "deal with facts, Discussions deal with points; facts are descriptive, while points are interpretive". Yet in another study, Samraj (2013) analyzed citation practices in discussion sections in Master's thesis as well as published research articles from one discipline with a view to facilitating L2 learners' knowledge construction in thesis writing. The findings showed various rhetorical functions in these sections both in theses and research articles. Petric and Harwood (2013) also reported on L2 student's citation practices in different types of writing tasks; however, not much is known on disciplinary variation in writing produced by non-native postgraduate students, hence the impetus behind the present study.

Moreover, a substantial rate of comments journal reviewers and viva examiners provide deal with citations. This, in turn, provides further impetus to explore citation practices of non-native graduate students across disciplines and, in this case, with different mediums of writing. This study, therefore, intends to identify types of citations in Master's thesis across four disciplines: two disciplines from hard knowledge fields and the other two from soft knowledge fields. The aim is to discover citation functions within DSs. Moreover, in this study, the language of writing a thesis, namely English or Persian, was also taken into account due to its probable relationship with the employed citation practices. 


\section{Corpus}

Thesis/dissertation writing is the most daunting and toughest task for many students (Sadeghi \& Shirzad 2015). This can be due to the size of the thesis or the high level of quality to which the dissertation or the thesis is held. The demanding part of thesis writing is not only the indication of knowledge related to the topic under analysis, but also the use of this knowledge to present arguments and claims convincingly along with the ability to interpret the findings of the study (Dong 1998). A thesis consists of several sections, the classification of which differs across disciplines. As Sadeghi and Shirzad (2015) point out, theses in hard disciplines are mostly written in three chapters (Introduction, Method, Results \& Discussion), while dissertations in soft knowledge fields consist of five chapters (Introduction, Literature Review, Method, Results \& Discussion, Conclusion). This format of dissertations is suggested by universities and students are required to follow the procedures closely.

In the present study, the focus was on DSs with the aim of discovering citation types and functions used by the authors. Thus, Introduction, Literature Review and Method sections were excluded from the corpus. According to Swales (1990: 170), Results and Discussion sections are merged at times and refer fleetingly to "additional or substituted sections labeled as conclusions, implications or applications and so on". Given this, in this research, discussions refer to the sections of theses under these headings: Results, Results and Discussion, Conclusion, Discussion and Conclusion.

In considering the scope of citations and the quantification of discrete occurrences of citations in so called discussion sections of the theses, we adhered to Swale's micro-structure perspective in which the citations are considered within a limited scope of the section referred to as Description. In contrast, in macro-structure view, citation strategies would be considered as scattered throughout the thesis as a whole or projected into various sections of the theses (Swales 1990). We admit the fact that the umbrella term of Thesis Discussion Sections could take a broad range of configurations and disciplinary variations so that the obtained figures are, in fact, rough estimations of citation strategies in 'fused sections' of theses, as it was nicely put by one of the anonymous reviewers. This is inevitable as, for example, in psychology theses the density of citations is achieved from a different configuration of sections in which Discussion configures with Conclusion, while, in the case of TEFL theses, the figures are based on Results and Discussion sections.

Accordingly, in the present study, the corpus consisted of $60 \mathrm{MA}$ thesis discussions sections produced by postgraduate students from two Iranian state 
universities. The theses were selected through stratified random sampling to obtain a proportionate number of thesis discussions randomly taken from each respective hard and soft science disciplines including chemistry (Chem.) and agriculture (Agri.) from hard knowledge fields plus TEFL and psychology (Psych.) from soft disciplines. Each discipline was represented by 15 thesis discussions from Urmia University and the University of Tabriz. All of the theses were written in Persian by Iranian postgraduate students except those produced by TEFL students who are required to compose their theses in English. The theses were submitted between the years 2007 and 2012, and were completed under the guidance of one supervisor and one advisor except for some rare cases of theses which had just one or two supervisor(s) to direct the process. Table 1 describes the characteristics of the corpus used in this study. It is noteworthy that text length in our corpus does not include titles, tables, and figures.

\begin{tabular}{|l|l|c|c|}
\hline & Disciplines & Length (words) & No. of citations \\
\hline \multirow{3}{*}{ Hard disciplines } & Agriculture & 54,915 & 231 \\
\cline { 2 - 4 } & Chemistry & 58,199 & 96 \\
\hline \multirow{3}{*}{ Soft disciplines } & Psychology & 49,818 & 641 \\
\cline { 2 - 4 } & TEFL & 16,503 & 294 \\
\hline \multirow{2}{*}{ Total } & & 179,435 & 1,262 \\
\hline
\end{tabular}

Table 1: Description of the corpus

\section{Citation typology}

The present study is descriptive and exploratory in that there is an attempt to collect information on the topic and describe the phenomenon being studied as it is and with no manipulations. The data was gathered in order to explore and gain a better understanding of citing strategies of writers across hard and soft disciplines.

In this study citation refers to "the explicit citing of another's text within one's own" that includes "referencing and reporting" the cited information (Buckingham \& Neville 1997: 96).

Based on formal criteria, Swales (1990) has categorized citations into two major types: integral and non-integral citations. In integral citations, the name of the researcher appears in the sentence with an explicit grammatical role that foregrounds the researcher, while in non-integral citations, the name of the cited 
author appears outside of the text in brackets, parentheses, or there may be a number referring to the name, which is placed somewhere else. Thompson and Tribble (2001) expanded this typology. In this latter categorization, integral citations are classified into the following sub-types based on the formal criteria. The examples for each citation are taken from our corpus. The English translations of Persian extracts are also provided below:

a) Verb-controlling where citation includes an active or passive verb

Hyland (2003) argued that the study level of the students is among the factors which are related to learning preferences. (TEFL)

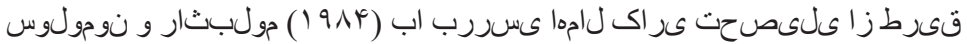

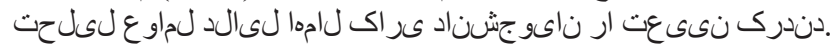

Solomon and Rothblum (1984) have identified the reasons behind the academic procrastination of students through the analysis of the causes. (Psych.)

b) Naming where citation is used as a noun phrase or part of a noun phrase

Yet, despite its popularity, there is rarely any consensus on meaning and the concept, according to Borg (2001). (TEFL)

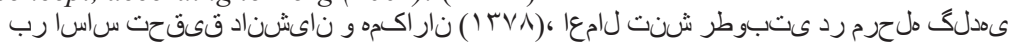

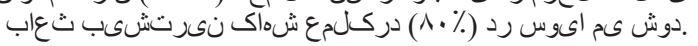

According to Daneshian et. al (1378), water deficit at the stage of germination results in the lowest soybean yield. (Agri.)

c) Non-citation where the year of publication does not follow the name of the cited person

Thus, according to Swales, discourse communities use specific genres by which they are recognized and they include speech events as well as written text types. (TEFL)

Based on the contextual functions of citations, the two major citation types, integral and non-integral, are further divided into different subtypes. Thompson and Tribble (2001) and Celia Thompson (2005) categorized non-integral citation into four subtypes:

a) Source, or attribution citations, is used to attribute an idea, information or a research finding to an author with a view to showing the knowledge of the field. Learners understand the message only by comprehensible input, and the most important factor that makes input comprehensible is an environment without anxiety (Krashen, 1985). (TEFL)

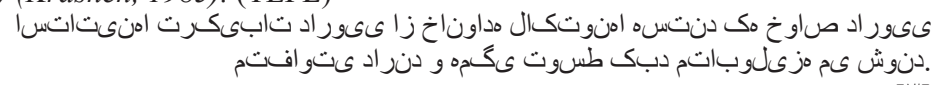


Statins are pharmaceutical compounds which belong to the family of lactones with different medicinal properties and all are metabolized by the liver. (Chem.)

b) Origin is used to indicate "the origin of a theory, technique or product" (Thompson, P. 2005).

The software package used was Wordsmith Tools (Scott 1996). (TEFL)

c) Reference is used to point to sources for further information and it usually includes the directive 'see' as in:

DFID has recently changed its policy with regard to ELT (see DFID, 1998). (TEFL)

d) Identification is used to identify particular texts or research projects mentioned in the sentence. An example of this type is:

Some studies reported that students obtained higher scores when interviewed by a male interviewer (Locke, 1984; Porter, 1991a; 1991b) while some others found that students got higher scores when interviewed by a female interviewer (Porter \& Shen 1991, O'Sullivan 2000). (TEFL)

This study investigated types of citations based on the syntactic positions of the name of the cited author in line with Swales (1990) and the functions of citations based on the writer's intention behind using citations. Thus, Thompson and Tribble's (2001) typology was mainly adopted; however, non-citation was not applicable in the case of the two groups of theses from hard disciplines since the used citation format was numbered and based on Vancouver referencing style or the author-number system. In this style, citations to others throughout the text are marked by the use of a number in brackets. At the end of the document, a sequentially numbered reference list provides complete information of the respective in-text references. This typology was then combined with two categories from Petrić's study which were applicable to DSs named as Comparison of one's own findings with other sources and Establishing links between sources, similar to the method used in Mansourizadeh and Ahmad's (2011) study. The category source was named as attribution, following Petrić (2007), in order to avoid confusion with the meaning of source that refers to the work by other authors which are used as source texts in one's writing.

After collecting the corpora, word count was carried out in order to determine the quantity and the length of the corpus. The types of citations in terms of integral or non-integral in each sub-corpus were identified and were classified into appropriate subtypes. Furthermore, the citation functions in each set of DSs were examined to account for the purposes for which citations were used by the writers and to see if there were any differences in the applications. It should be 
noted that, following Thompson and Ye (1991), in this study the citing person is referred to as the 'writer' and the cited person as the 'author'.

The overall density of citations and their density in different sections of the theses were measured. The occurrence of each function in discussion sections was calculated using the chi-square value to see if there was statically significant difference between the sets of discussions in terms of citation practices. To ensure reliability of the analysis in the process of data categorization, one third of the data (i.e. five theses from each discipline) was rechecked and reanalyzed independently for citation types and functions by a second researcher (an MA graduate of TEFL from Tabriz University), who was briefed on the purpose of the study by the researchers. She was well informed on the categorization of types and functions of citations in order for her to be able to analyze the data. The obtained correlation coefficient (inter-rater reliability $=0.97$ ) between the two ratings was high enough to make the analysis reliable.

\section{Results and discussion}

\subsection{Citations in thesis sub-sections}

In this part, the density of citations (per 1,000 words) in different sections of the theses is presented. Figure 1 shows citation density in different parts of the theses written by MS students from hard knowledge fields, namely agriculture and chemistry.

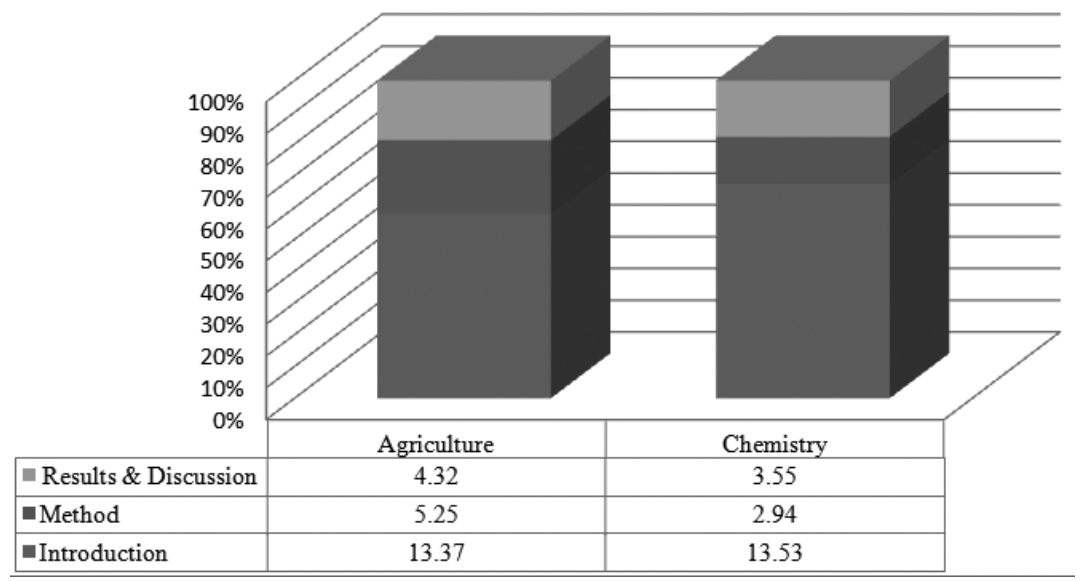

Figure 1: Citation density in different sections of hard knowledge fields 
As Figure 1 shows, in both agriculture and chemistry theses, citations were densely used in the Introduction section the extent of which was roughly the same for all writers (Introduction in agriculture $=13.37$; Introduction in chemistry $=13.53$ ). This finding confirms the results of the study by Celia Thompson (2005), in which she found that writers employed citations more often in the Introductions in order to put their study in a bigger and appropriate context, to recapitulate the related literature, and to identify a gap for their own research. Contrary to what has been discovered in Thompson's research, the findings of the present study showed that the second sections in which citations were heavily used in agriculture and chemistry were the Method and Results-discussion sections respectively.

As far as the theses from soft knowledge fields (psychology and TEFL) are concerned, they consist of five chapters; however, citation density in different sections of these texts is presented separately in separate tables. Thus, Tables 2 and 3 present the density of citation in different chapters of the theses produced by Master's students in psychology and TEFL.

\begin{tabular}{|l|c|}
\hline Sections & Density \\
\hline Introduction & 17.74 \\
\hline Literature Review & 10 \\
\hline Method & 5.72 \\
\hline Results & 0.9 \\
\hline Discussion \& Conclusion & 16.92 \\
\hline
\end{tabular}

Table 2: Citation density in different sections of psychology theses

\begin{tabular}{|l|c|}
\hline Sections & Density \\
\hline Introduction & 18.8 \\
\hline Literature Review & 24.21 \\
\hline Method & 3.49 \\
\hline Results \& Discussion & 2.77 \\
\hline Conclusion & 2.12 \\
\hline
\end{tabular}

Table 3: Citation density in different sections of TEFL theses 
As can be concluded from the tables, citations were densely used in Introduction sections of the theses written by psychology students, whereas they were mostly used in the Literature Review sections of TEFL theses followed by Introduction. In psychology theses, the second-highest citation density belonged to Discussion and Conclusion followed by Literature Review and then Method section. Citations were seldom, if ever, used in Results. In the theses produced by TEFL students, see Table 3, after Literature Review and Introduction, the Method section had the highest citation density. Results, Discussion, and Conclusion sections occupied the next ranks in terms of citation density.

The quantitative analysis revealed disciplinary variation in the extent to which the writers of different disciplines referred to other authors while putting forward their arguments. Table 4 presents this disciplinary variation across disciplines in terms of citation use.

\begin{tabular}{|l|l|c|c|}
\hline Rank & Discipline & Density & Total citations \\
\hline 1 & TEFL & 17.81 & 294 \\
\hline 2 & Psychology & 12.86 & 641 \\
\hline 3 & Agriculture & 4.2 & 231 \\
\hline 4 & Chemistry & 1.64 & 96 \\
\hline
\end{tabular}

Table 4: Rank order of citations by discipline

As illustrated in Table 4, soft knowledge fields tend to use citations more than hard disciplines in the discussion section with TEFL having the highest rank among other fields and chemistry the lowest. As Hyland (1999) points out, softer disciplines tend to use more citations.

\subsection{Differences in types of citation}

In addition to the density of occurrences of citations in each section of the theses, the types of citations characterizing the discussion sections written by the students in each sub-corpus were also identified. Table 5 shows the frequency of citation types, integral and non-integral, in the texts created by MS students from two fields of agriculture and chemistry. 


\begin{tabular}{|l|c|c|}
\hline \multirow{2}{*}{ Types of citations } & \multicolumn{2}{|c|}{ Hard disciplines } \\
\cline { 2 - 3 } & Agriculture & Chemistry \\
\hline Non-integral & $107(46.32 \%)$ & $96(100 \%)$ \\
\hline Integral & $124(53.68 \%)$ & $0(0 \%)$ \\
\hline Integral-verb controlling & $52(22.51 \%)$ & $0(0 \%)$ \\
\hline Integral-naming & $72(31.17 \%)$ & $0(0 \%)$ \\
\hline Non-citation & $0(0 \%)$ & $0(0 \%)$ \\
\hline Total & 231 & 96 \\
\hline
\end{tabular}

Table 5: Types of citation in MA discussion sections for hard disciplines

The findings shown in Table 5 revealed that in the field of agriculture, integral citations were used dominantly while in discussions written by chemistry students only non-integral citations were used, to the exclusion of other types. According to Hyland $(1999,2000)$, non-integral citations are expected to be dominantly used by writers in hard sciences, whereas writers in soft disciplines prefer integral ones in order to foreground the role of writers from source text; however, agriculture discussions did not fit into this general picture. This result may be explained referring to Hyland (1999), who views disciplines as a continuum along which there are softer and harder disciplines.

In order to examine the differences of the types of citation in the two disciplines of agriculture and chemistry, chi-square test was employed. The results indicated a statistically significant difference, $\chi^{2}=80.74(1 d f, p<.05)$. Yates' chi-square is reported for 1-df tests. Chi-square test revealed that the difference in the use of citation types in hard texts was significant. Similarly, Table 6 presents the frequency of citation types in the discussions produced by Master's students in soft knowledge fields. 


\begin{tabular}{|l|c|c|}
\hline \multirow{2}{*}{ Types of citations } & \multicolumn{2}{|c|}{ Soft disciplines } \\
\cline { 2 - 3 } & Psychology & TEFL \\
\hline Non-integral & $169(26.37 \%)$ & $77(26.19 \%)$ \\
\hline Integral & $472(73.63 \%)$ & $217(73.81 \%)$ \\
\hline Integral-verb controlling & $129(20.12 \%)$ & $84(28.57 \%)$ \\
\hline Integral-naming & $313(48.83 \%)$ & $130(44.22 \%)$ \\
\hline Non-citation & $30(4.68 \%)$ & $3(1.02 \%)$ \\
\hline Total & 641 & 294 \\
\hline
\end{tabular}

Table 6: Types of citations in MA discussion sections for soft disciplines

As can be seen from Table 6, integral citations were mostly used by the writers in psychology and TEFL. The data analysis revealed that naming citations were dominant in the discussions produced by both psychology and TEFL students and non-citation was rarely used in these text types (psychology $=4.68 \%$; $\mathrm{TEFL}=1.02 \%$ ). In order to find out whether there was a significant difference in the types of citation used by Iranian MA students in the discussion sections of theses across two disciplines of psychology and TEFL, another chi-square test was used assuming significance level of 0.05 . The results showed no significant differences in citation types, integral and non-integral, in discussions written by these two groups of writers $\chi^{2}=0.001$ ( $\left.1 d f, p>.05\right)$. Non-integral citations, as Charles (2006a) states, are prevalent in hard disciplines in order to foreground the research and give less prominence to the researchers, while the use of integral citations in soft disciplines provides the writer with a pronounced role, allowing evaluations on their part.

\subsection{Differences in functions of citation}

Functions of citation were also examined in the present study. The aim was to discover the intention with which citations were employed by the writers across disciplines. Table 7 presents the total number of functions identified in different sets of discussions as well as the dominant citation function in each sub-corpus. 


\begin{tabular}{|l|c|c|}
\hline \multirow{2}{*}{ Citation functions } & \multicolumn{2}{|c|}{ Hard disciplines } \\
\cline { 2 - 3 } & Agriculture & Chemistry \\
\hline Attribution & $85(34 \%)$ & $24(25 \%)$ \\
\hline Support & $110(44 \%)$ & $63(65.63 \%)$ \\
\hline Comparison & $40(16 \%)$ & $9(9.37 \%)$ \\
\hline Establishing links & $15(6 \%)$ & $0(0 \%)$ \\
\hline Identification & $0(0 \%)$ & $0(0 \%)$ \\
\hline Reference & $0(0 \%)$ & $0(0 \%)$ \\
\hline Total & 250 & 96 \\
\hline
\end{tabular}

Table 7: Functions of citations in MA discussion sections for hard disciplines

The findings indicated that Support was the most frequent function in both of the hard disciplines with a frequency of 110 in agriculture $(f=110)$, accounting for 44 per cent of the functions identified in the discussions, and a frequency of $63(f=63)$ in chemistry. As Table 7 shows, the second and third most frequent functions were Attribution and Comparison respectively. The least frequent function was Establishing links $(f=15)$ including six per cent of 250 functions identified in agriculture texts, whereas no instance of this type was observed in chemistry discussions. Besides, no citations with the function of Identification and Reference were detected in discussions written by these two groups of writers.

Chi-square test showed a significant difference between the citation functions employed by Iranian MS students in the discussion sections of theses across two disciplines of TEFL and psychology, $\chi^{2}=13.73(3 d f, p<.05)$.

Table 8 illustrates the total number of functions identified in psychology and TEFL discussions as well as the frequency of each function. 


\begin{tabular}{|l|c|c|}
\hline \multirow{2}{*}{ Citation functions } & \multicolumn{2}{|c|}{ Soft disciplines } \\
\cline { 2 - 3 } & Psychology & TEFL \\
\hline Attribution & $50(7.3 \%)$ & $0(0 \%)$ \\
\hline Support & $115(16.79 \%)$ & $224(67.47 \%)$ \\
\hline Comparison & $435(63.5 \%)$ & $92(27.71 \%)$ \\
\hline Establishing links & $85(12.4 \%)$ & $16(4.82 \%)$ \\
\hline Identification & $0(0 \%)$ & $0(0 \%)$ \\
\hline Reference & $0(0 \%)$ & $0(0 \%)$ \\
\hline Total & 685 & 332 \\
\hline
\end{tabular}

Table 8: Functions of citations in MA discussion sections for soft disciplines

In total, 685 citation functions were identified in psychology discussions and 332 in TEFL discussions with Comparison being the most frequent citation function in psychology $(f=435)$. The results of chi-square test showed a great difference, $\chi^{2}=260.38(3 d f, p<.05)$ in the use of citation functions by these writers, meaning that these two groups of writers employ citations in thesis discussions with different purposes.

The function of Comparison was mainly used to call the readers' attention to the similarities of the results with previous studies. Alternatively, in the case of soft knowledge fields, it was mostly used to bring the dissimilarities to their attention. Yet, the question remains as to why writers construct something in order to overtly attack it later through reference to previous research. By means of this citation strategy, according to Swales and Feak (1994: 57), students "position themselves as being informed". They can be very effective in their presentation of themselves via both clever emphasis on the strong points of their work and clever stress on its weaknesses. This citation function, that is, when the writers compare their own findings with previous ones, can result in higher acceptability as well as greater credibility of the results. This can be due to the fact that employing a plenty of sources in writing may contribute to its factual status (Latour \& Woolgar 1979). As the analysis of the corpus indicated, the writers could employ this citation function frequently in discussions due to its less demanding nature.

In TEFL discussions, however, Support has the highest frequency $(f=224)$ accounting for 67.47 per cent of the functions observed in this sub-corpus, whereas it is the second most frequent function in psychology texts with 
Establishing links $(f=85)$ being next, which allows the writer to demonstrate his knowledge of the field thereby increasing the acceptability of his claims and arguments by the members of that discourse community to which he belongs.

It should be noted that Support is a complex citation function and it needs disciplinary knowledge on the part of the writer and it can be used for the justification of findings, arguments and claims, and the topic of the research. Mansourizadeh and Ahmad (2011) found that Support was mainly used by experts and novices rarely employed this function. Thus, this function can indicate the writer's ability and experience of conducting research. It was used densely in the corpus of this study by students in Master's program who are not considered as experts in their fields. This finding was also reported in Samraj's (2013) study. She found that students can also employ more complex citation functions in thesis discussions as expert writers do in published articles. However, in the use of such citation functions as Support, 'how and to what effect' is what should be taken into account. The writers mostly used it to 'announce' the similar or different findings reported by others without actually comparing their own findings with those of others, while they should be cognizant of the fact that discussion means something beyond mere report of other results (Hyland 1998), either similar or different. The way in which they establish links between sources on the one hand, and their own study on the other is what matters so that they could come up with convincing and effective pieces of text.

Moreover, this study tried to find out whether there was any significant difference between citation types used in the discussion sections of theses by Iranian postgraduate students from hard disciplines and soft disciplines. Chisquare test showed a meaningful difference in the citation types used by writers in hard knowledge fields and soft disciplines, $\chi^{2}=135.2(1 d f, p<.05)$. Likewise, in terms of citation functions, we again found a significant difference between hard and soft disciplines, $\chi^{2}=271.6(3 d f, p<.05)$.

Petrić's (2007) study showed that Attribution was the main one in low graded Master's students' theses compared to high graded ones. In our study, this citation function was used in discussion sections written by agriculture, chemistry, and psychology students and to a degree that could not go unnoticed (agriculture $=34 \%$; chemistry $=24 \%$; psychology $=7.3 \%$ ). In hard disciplines, it was the second mostly used function, but TEFL students did not make use of Attribution in their discussions. In addition, no instances of Identification and Reference were found in texts written by TEFL and psychology students.

Attribution is a basic citation function through which writers show their knowledge of the field and the related literature and it is "rhetorically the simplest citation function" (Petrić 2007: 247) which does not require advanced skills to 
use. As such, it is not an appropriate function for discussion sections since, as Celia Thompson (2005) argues, it is of overriding importance for writers to use their own voice, power, and ability in their writing and they ought to present themselves as authors. In the corpus, TEFL writers did not employ this function in discussion sections and this might have something to do with the medium of writing. Since they are supposed to write in English, they are more engaged with articles and academic texts written in this very language and they are more familiar with these text types. As observed in the corpus, they could use citations more effectively compared to the other groups of writers in support of their findings as well as their claims. Of course, it should be added that they need to be instructed on effective ways to present their ideas and justify their contributions to the field through strategic use of citations, that is, to polish their citing skills. However, in general, they were more skillful in presenting their arguments and creating links between sources which was not the case with writers in the other disciplines.

\section{Concluding remarks}

Although this research highlights a number of interesting issues, some limitations must be acknowledged. One problem is related to identifying citation functions and the writer's intention of using references that are not easily extractable from the context. This issue can be approached by supplementing context analysis and interviews to discover the rhetorical purposes behind citation patterns.

Besides, citations in more than one discipline were examined in this research. In such cases, lack of specialized knowledge might make the analysis more difficult for the researcher. It may be argued that students learn to produce scientific texts by having access to the published articles or completed theses; however, several different writing features such as citation practices, among others, may remain uncovered for novice writers. In addition, scholars and students write for different types of audience and work toward different writing goals in different genres, all of which could influence their citation practices.

Seasoned researchers usually cite their peers, while students make references to the studies carried out by those with a superior status, where, as Petrić (2007) notes, issues of power are not similar and this might affect their evaluations of others and the confidence with which they do so. Furthermore, non-integral citations, as Hewings et al. (2010) note, aid the writer in keeping the flow of the argument uninterrupted. It would be a seamless presentation of points. The same holds true for all the disciplines in the present study except agriculture, which differed from this general picture. 
A good number of implications would arise from this study. For one thing, there is providing researchers, teachers and syllabus designers with more wellfashioned insights into the nature of texts produced by MA/MS students when discussing their points toward the achievement of certain goals on their part. Besides, further research into the citation practices could be facilitated and induced via this study, either within the genre of Master's theses or other genres, not to mention the suggested implications for non-native postgraduate students to improve the text type in their proposals or theses. The findings, therefore, could offer opportunities for teaching academic writing to novices who are trying to produce a thesis or a research article "to join the research community as an insider" (Akiko 2007: 69). This study also carries wider implications in terms of generic awareness on the issue; the findings can be of considerable help to EAP instructors, thesis supervising bodies, and advanced writing course instructors in order to raise their students' awareness and refine their understanding of sound types and functions of citation practices in thesis writing.

\section{References}

Akiko, O. (2007) 'Writer's intention behind the citation forms in academic texts.' The Economic Journal of Takasaki City University of Economics 49/3, 4, 57-70.

Bazerman, C. (1988) Shaping Written Knowledge: The Genre and Activity of the Experimental Article in Science. Madison: University of Wisconsin Press.

Buckingham, J. and Neville, M. (1997) 'Comparing the citation choices of experienced academic writers and first year students.' In: Golebiowski, Z. (ed.) Policy and Practice of Tertiary Literacy. Melbourne: Victoria University of Technology. 96-108.

Charles, M. (2006a) 'Phraseological patterns in reporting clauses used in citation: A corpus-based study of theses in two disciplines.' English for Specific Purposes 25, 310-331.

Charles, M. (2006b) 'The construction of stance in reporting clauses.' Applied Linguistics 27, 492-518.

Dong, Y. R. (1996) 'Learning how to use citation for knowledge transformation: Nonnative doctoral students' dissertation writing in science.' Research in the Teaching of English 30/4, 428-457.

Dong, Y. R. (1998) 'Non-native graduate students' thesis/dissertation writing in science: Self-reports by students and their supervisors from two US institutions.' English for Specific Purposes 17/4, 369-390.

Harwood, N. (2009) 'An interview-based study of the functions of citation in academic writing across two disciplines.' Journal of Pragmatics 41, 497-518.

Hawes, T. and Thomas, S. (1997) 'Tense choices in citations.' Research in the Teaching of English 31, 394-414.

Hewings, A., Lillis, T. and Vladimirou, D. (2010) 'Who's citing whose writings? A corpus base study of citations as interpersonal resource in English medium national and English medium international journals.' Journal of English for Academic Purposes 9, 102-115.

$\mathrm{Hu}, \mathrm{G}$. and Wang, G. (2014) 'Disciplinary and ethnolinguistic influences on citation in research articles.' Journal of English for Academic Purposes 14, 14-28. 
Hyland, K. (1998) Hedging in Scientific Research Articles. Amsterdam: John Benjamins. Hyland, K. (1999) 'Academic attribution: Citation and the construction of disciplinary knowledge.' Applied Linguistics 20/3, 341-367.

Hyland, K. (2000) Disciplinary Discourses: Social Interactions in Academic Writing. Harlow: Longman.

Hyland, K. (2002) 'Authority and invisibility: Authorial identity in academic writing.' Journal of Pragmatics 34, 1091-1112.

Latour, B. and Woolgar, S. (1979) Laboratory Life. The Social Construction of Scientific Facts. Sage: London.

Mansourizadeh, K. and Ahmad, U. K. (2011) 'Citation practices among non-native expert and novice scientific writers.' Journal of English for Academic Purposes 10, 152-161.

Mur Dueñas, P. (2009) 'Citation in business management research articles: A contrastive (English-Spanish) corpus-based analysis.' In: Suomela-Salmi, E. and Dervin, F. (eds) Cross-Linguistic and Cross-Cultural Perspectives on Academic Discourse. Amsterdam, the Netherlands: John Benjamins. 49-60.

Pecorari, D. (2006) 'Visible and occluded citation features in postgraduate secondlanguage writing.' English for Specific Purposes 25/1, 4-29.

Pennycook, A. (1996) 'Borrowing others' words: Text, ownership, memory, and plagiarism.' TESOL Quarterly 30/2, 201-230.

Petrić, B. (2007) 'Rhetorical functions of citations in high- and low-rated Master's theses.' Journal of English for Academic Purposes 6, 238-253.

Petrić, B., and Harwood, N. (2013) 'Task requirements, task representation, and selfreported citation functions: An exploratory study of a successful L2 student's writing.' Journal of English for Academic Purposes 12, 110-124.

Sadeghi, K. and Shirzad, A. (2015) 'Thesis writing challenges for non-native MA students.' Research in Post-Compulsory Education 20/3, 357-373.

Samraj, B. (2008) 'A discourse analysis of Master's theses across disciplines with a focus on introductions.' Journal of English for Academic Purposes 7, 55-67.

Samraj, B. (2013) 'Form and function of citations in discussion sections of Master's theses and research articles.' Journal of English for Academic Purposes 12, 299-310.

Shooshtari, Z. G. and Jalilifar, A. (2010) 'Citation and the construction of disciplinary knowledge.' Journal of Teaching Language Skills 2/1, 45-66.

Smith, L. C. (1981) 'Citation analysis.' Library Trends 30, 83-106.

Swales, J. M. (1986) 'Citation analysis and discourse analysis.' Applied Linguistics 7/1, 39-56.

Swales, J. M. (1990) Genre Analysis: English in Academic and Research Setting. Cambridge: Cambridge University Press.

Swales, J. and Feak, C. (1994) Academic Writing for Graduate Students. Ann Arbor, MI: The University of Michigan.

Thompson, C. (2005) 'Authority is everything: A study of politics of textual ownership and knowledge in the formation of student writer identities.' International Journal for Educational Integrity 1/1, 1-12.

Thompson, G. and Ye, Y. (1991) 'Evaluation in the reporting verbs used in academic papers.' Applied Linguistics 12, 365-382.

Thompson, P. (2005) 'Points of focus and position: Intertextual reference in $\mathrm{PhD}$ theses.' Journal of English for Academic Purposes 4, 307-323.

Thompson, P. and Tribble, C. (2001) 'Looking at citations: Using corpora in English for academic purposes.' Language Learning \& Technology 5/3, 91-105.

White, H. D. (2004) 'Citation analysis and discourse analysis revisited.' Applied Linguistics 25, 89-116. 
Raheleh Bahadorfar holds MA degree in TEFL from Urmia University, Iran. She is an experienced EFL and ESP teacher. Her research interests are genre analysis and academic writing in EAP.

Address: Raheleh Bahadorfar, English Language Department, Urmia University, Urmia 165, Iran. [e-mail: r.bahadorfar@gmail.com]

Javad Gholami is Assistant Professor in Teaching English to Speakers of Other Languages (TESOL) from Urmia University, Iran. His main publications have been on incidental focus on form, teacher education, academic writing, and convenience editing. He co-edits Journal of Teacher Education for Sustainability.

Address: Javad Gholami, English Language Department, Urmia University, Urmia 165, Iran. [e-mail: j.gholami@urmia.ac.ir] 
